\title{
Importância da alimentação durante a pandemia
}

DOI: dx.doi.org/10.18616/nrm09

Antônio Augusto Schäfer Fernanda de Oliveira Meller Micaela Rabelo Quadra

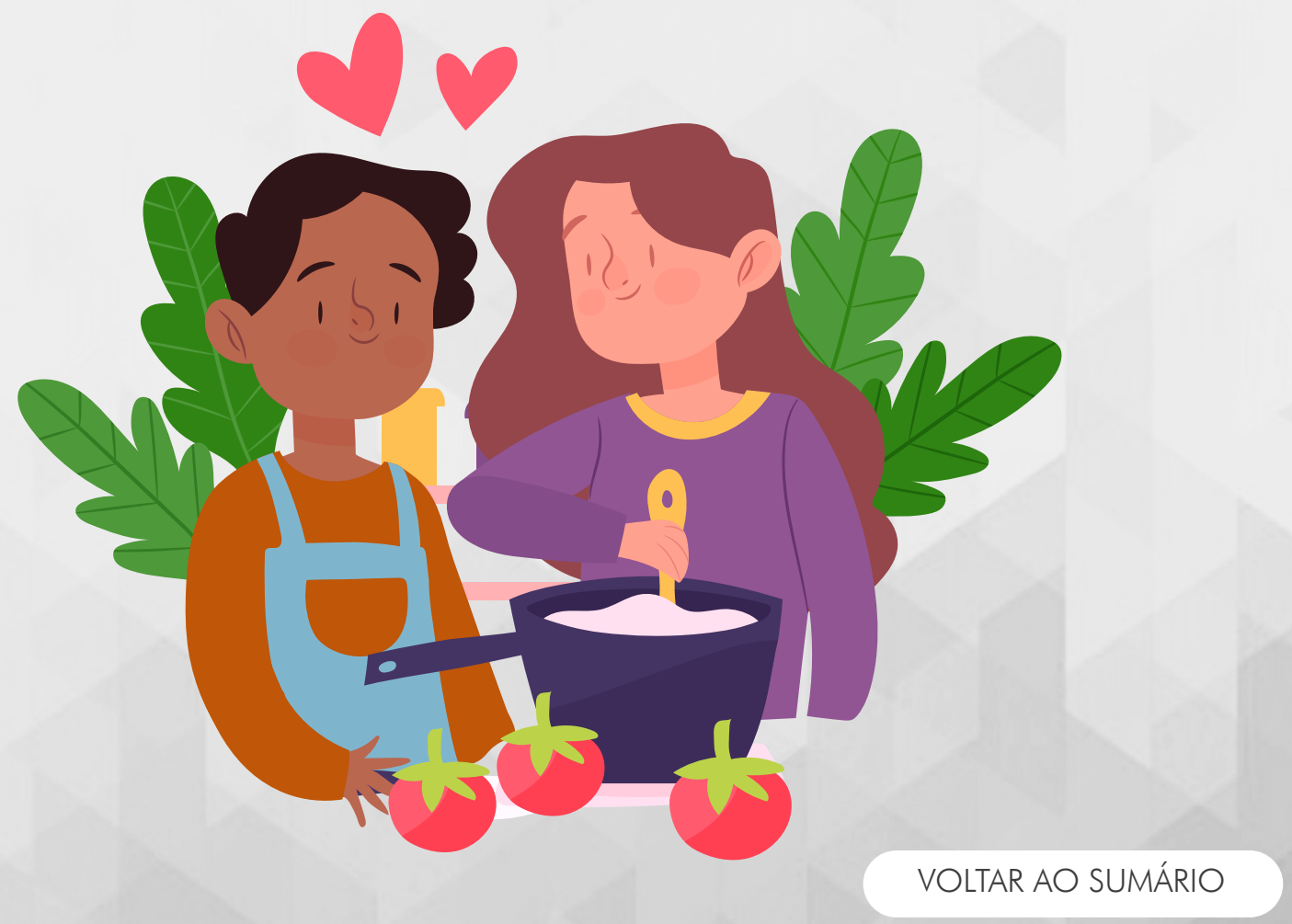


A REGRA DE OURO

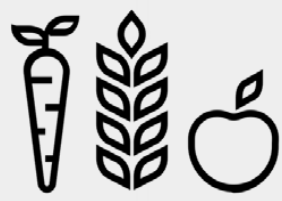

\section{Prefira sempre alimentos in natura ou minimamente proces- sados a alimentos ultraprocessados;}

Faça dos alimentos in natura ou minimamente processados a base de sua alimentação;
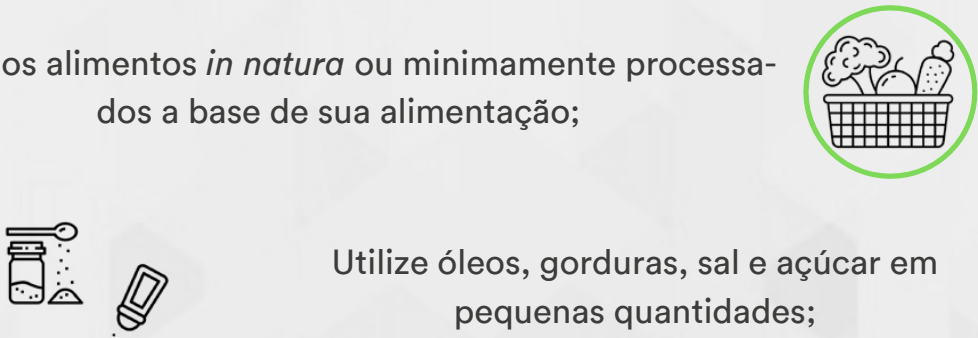

Utilize óleos, gorduras, sal e açúcar em pequenas quantidades;

Limite o uso de alimentos industrializados (processados e ultraprocessados).

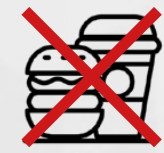

Fonte: (BRASIL, 2014).

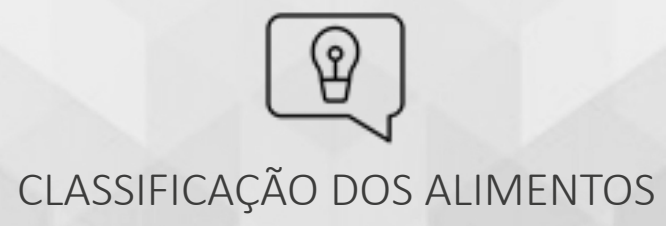

1 - Alimentos in natura ou minimamente processados: aqueles que não passaram por nenhum, ou por um mínimo, processamento na indústria. Exemplos: frutas, verduras, cereais, leguminosas, carnes.

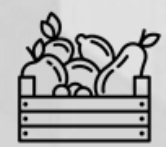




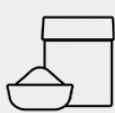

今

2. Ingredientes culinários processados: ingredientes

extraídos do primeiro grupo. Exemplos: sal, açúcar, óleos, mel.

3. Alimentos processados: alimentos do grupo 1, com ingredientes do grupo 2 adicionados à sua composição, tornando-se industrializados. Exemplos: compotas, conservas, frutas cristalizadas.
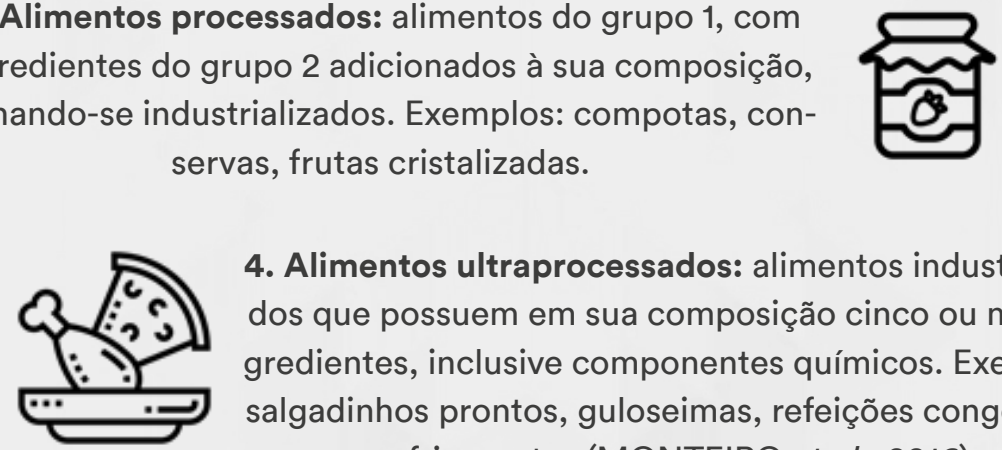

4. Alimentos ultraprocessados: alimentos industrializados que possuem em sua composição cinco ou mais ingredientes, inclusive componentes químicos. Exemplos: salgadinhos prontos, guloseimas, refeições congeladas, refrigerantes (MONTEIRO et al., 2016).

\section{O ATO DE COMER}

A alimentação vai muito além da necessidade energética. Ela é responsável por manter o pleno desenvolvimento e a manutenção de todo o nosso organismo, inclusive de nossa saúde. Algumas estratégias são importantes e auxiliam-nos na manutenção de uma alimentação saudável e adequada.

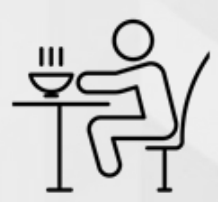

Regularidade e atenção

Escolha horários similares para a realização de suas refeições. Coma devagar, com calma, mastigando bem e desfrutando de seu alimento.

\section{Escolha ambientes apropriados para}

\section{realizar suas refeições}

Locais limpos, tranquilos e sem distrações (como celular, televisão, etc.). Procure concentrar-se na realização de sua refeição.

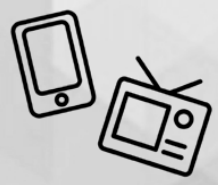




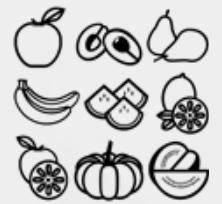
Não se esqueça de evitar "beliscar" entre as refeições Quando ansiosos, ficamos com vontade de comer constan- temente. Procure evitar esse hábito e a escolha por salgados ou doces industrializados. Opte sempre por alimentos mais saudáveis como as frutas frescas.

\section{Participe do planejamento das refeições}

Participar do planejamento, da compra, do preparo, do servimento e/ou da limpeza de utensílios favorece a criação de vínculo e o compartilhamento entre as pessoas.

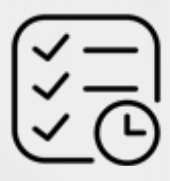

\section{Habilidades culinárias}

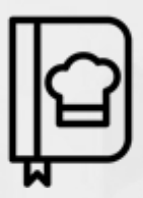

Este pode ser o momento para recuperar os livros de receitas e/ou realizar novas preparações. Partilhe este momento e valorize não somente o ato de comer, mas também o ato de preparar os alimentos. Atividades como essa podem servir como distração e dar a sensação de contentamento no momento atual.

\section{Organize seu tempo}

Planeje sua alimentação, seja nas compras ou no preparo das refeições. Organizar uma rotina alimentar agora poderá facilitar e melhorar a sua alimentação quando voltar à rotina.
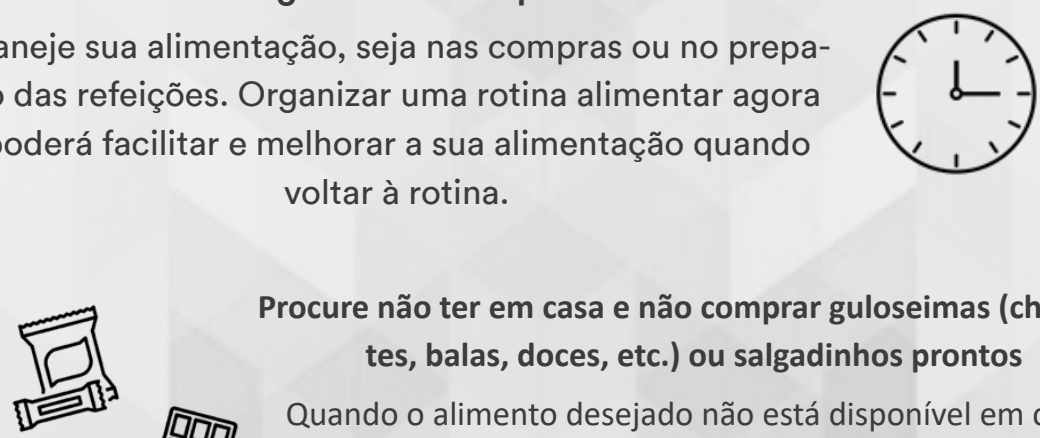

Procure não ter em casa e não comprar guloseimas (chocolates, balas, doces, etc.) ou salgadinhos prontos Quando o alimento desejado não está disponível em casa, dificilmente você se dará ao trabalho de sair para realizar a compra, especialmente durante a pandemia. 
Realize de cinco a seis refeições diárias, todas em horários adequados

Manter uma rotina de alimentação reduz a vontade de "beliscar" e a procura por alimentos industrializados.
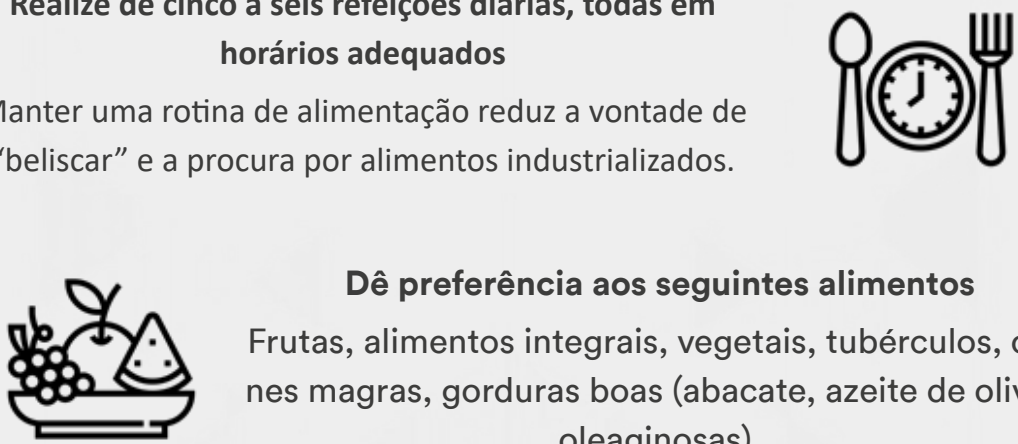

Dê preferência aos seguintes alimentos Frutas, alimentos integrais, vegetais, tubérculos, carnes magras, gorduras boas (abacate, azeite de oliva e oleaginosas).

Seja crítico(a) com as informações sobre alimentação que aparecem na mídia!

Não é o momento para dietas da "moda" ou para alimentos "milagrosos". Sempre procure fontes consideradas confiáveis quanto às informações.

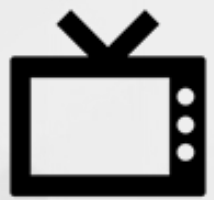

\section{Não se esqueça de tomar água!}

Consuma, todos os dias, pelo menos 2 litros de água ou calcule sua necessidade diária: $30 \mathrm{ml}$ de água $X$ seu peso. Exemplo:

\section{$30 \mathrm{ml} \times 65 \mathrm{~kg}=1950 \mathrm{ml}$ de água $/$ dia .}

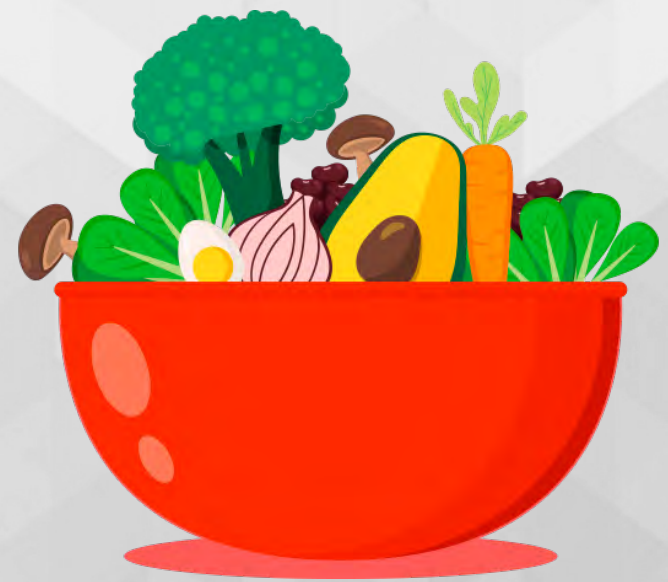




\section{?}

NUTRIENTES

\section{Uma alimentação equilibrada, rica em alimentos in natura ou minimamente processados e sem alimentos industrializados é a chave para a oferta de to- dos os nutrientes e para o fortalecimento da imunidade.}

Veja que alguns nutrientes desempenham importantes papéis no sistema imunológico. São eles:

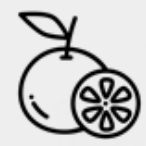

毁
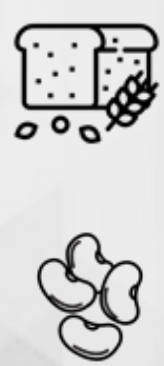

Fontes: carne bovina, feijão, couve, espinafre e brócolis.

Fontes: fígado, mamão, cenoura e abóbora.

\section{Cobre}

Fontes: feijão, lentilha e cereais integrais.
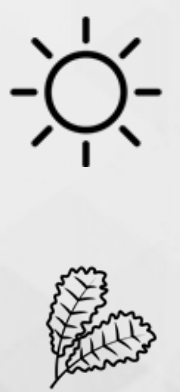

Fontes: castanhas, fígado, vegetais verde-escuros, óleos vegetais e abacate. vísceras e ovos.

Vitamina $E$

Fontes: luz solar, peixes (sardinha, atum e arenque),

Zinco

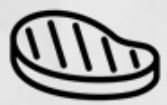

Fontes: carnes, fígado e castanha de caju.

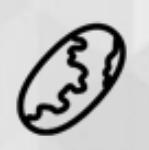

Selênio:

Fontes: castanha-do-brasil, farinha de trigo integral e aveia.

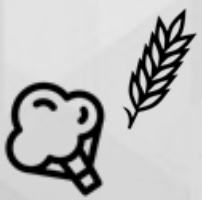

\section{Complexo B}

Vitaminas B6, B12 e B9. Fontes: carnes vermelhas, cereais integrais, feijão, lentilha e vegetais verde-escuros.

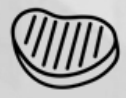




\section{回 \\ A ALIMENTAÇÃO E A SAÚDE MENTAL}

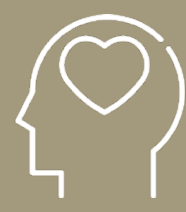

Evidências sugerem que alguns nutrientes e padrões alimentares atuam modulando, tanto positiva como negativamente, a nossa saúde mental, estando associados até mesmo à depressão e à ansiedade.

O padrão alimentar conhecido como Dieta do Mediterrâneo, constituído por ácidos graxos mono e poliinsaturados; polifenóis; vitaminas $A, B 6$, B12, B9, C, E, D; minerais como ferro, zinco e selênio; além de aminoácidos precursores, desempenha papel protetor não somente para a saúde física, mas também para a saúde mental.

Sendo assim, procure ter no seu padrão alimentar a presença dos seguintes alimentos:

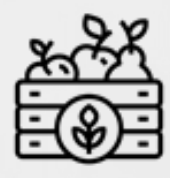

Frutas e vegetais frescos

Especialmente as frutas cítricas, os vegetais verde-escuros e as leguminosas como o feijão.

\section{Carnes magras}

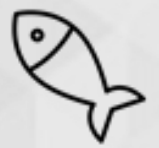

Especialmente peixes como atum, sardinha e arenque.
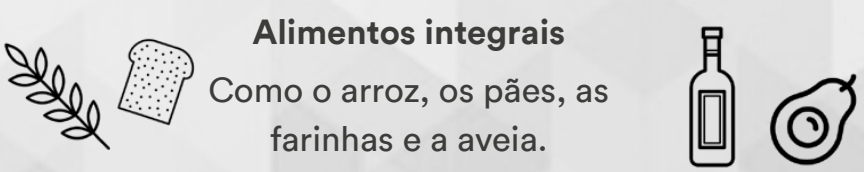

Gorduras boas

Castanhas, abacates e óleos vegetais como o azeite de oliva.

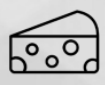

\section{Leite e derivados com baixo teor de gordura} Como os queijos brancos e leite semi ou desnatado. 